\title{
LO BELLO NATURAL, LO BELLO ROMÁNTICO, EL KITSCH, LA VANGUARDIA Y EL CARÁCTER ENIGMÁTICO DE LA OBRA DE ARTE EN TH. W. ADORNO
}

\section{NATURAL BEAUTY, ROMANTIC BEAUTY, KITSCH, THE VANGUARD AND THE ENIGMATIC CHARACTER OF THE WORK OF ART IN TH. W. ADORNO}

\author{
Juan Ramón Búa SONEIRA* \\ Universidad Nacional de Educación a Distancia (UNED)
}

Resumen: El propósito de este trabajo reside en la aclaración y, a la vez, amplificación de algunos pasajes importantes de la Teoría estética y otros textos de Th. W. Adorno donde, de un modo fragmentario, se apela al curso histórico que va desde lo bello natural y lo bello romántico hasta la vanguardia y el kitsch. Para ello, se tomará la referencia de Adorno a Greenberg como punto de llegada de la discusión estética establecida entre Kant y Hegel. Así también, para finalizar, se alude al carácter enigmático de la obra de arte, a partir del cual, Adorno expone la dificultad de comprender la obra a partir del receptor y oyente en su necesidad de mediación entre forma y contenido, esto es, entre la autonomía estética y el fait social que componen la obra misma

Palabras clave: Adorno, Estética, Belleza, Kitsch, Vanguardia.

* Doctor en Filosofía (UNED), mon.bua.soneira@gmail.com. 
Aвsтract: This paper aims to clarify important passages of Th. W. Adorno's Aesthetics Theory and other texts that follow, in a fragmentary way, the historical course from natural beauty and romantic beauty to vanguard and kitsch. To do this, Adorno's reference to Greenberg is taken as the arrival point of the aesthetic discussion established by Kant and Hegel. Also, to conclude, the enigmatic character of the work of art is referred to, which Adorno uses to explain the difficulty of understanding the work of art from the receiver and listener in their need for mediation between form and content, between the aesthetic autonomy of the work of art and the fait social that is contained in it.

KeYwords: Adorno, Aesthetics, Beauty, Kitsch, Vanguard.

\section{Introducción}

Adorno expresa en la inacabada Teoría estética, publicada en 1969, que, desde Schelling, cuando a la estética se le llamaba filosofía del arte, el interés estético de las teorías apenas ocupa el lugar de lo bello natural, en lo que todavía se basaba Kant en la Crítica del juicio (Adorno, 2014, 88). La decadencia de lo bello no viene dada únicamente por su contraposición dialéctica con la categoría de lo feo de Baudelaire (2016), sino que tiene su explicación en el dominio cada vez más amplio de conceptos como libertad y dignidad humana inaugurados por Kant y puestos en viraje por Hegel o por la estética de Schiller. Para Adorno, de acuerdo con Hegel, en el mundo no hay que respetar más que aquello que el sujeto autónomo se debe a si mismo, pero en la verdad de esa libertad del sujeto radica al mismo tiempo la falsedad (falta de libertad para lo otro) (Adorno, $2014,89)$. Así se da el giro de lo bello natural hacia un progreso de la libertad que acaba en algo meramente espiritual, histórico, donde se enfrenta la dignidad con la naturaleza. La belleza ya no consiste en la categoría estética del placer por la mímesis a través de la cual se imitan las cosas de la realidad, lo bello natural no solo es inmanente a lo bello artístico, sino que el sujeto artista, bajo su deseo de emancipación pretende volar más allá de la naturaleza para encontrarse con sí mismo y penetrar la dimensión espiritual, que en sentido último es Dios.

Kant en el epígrafe $\$ 42$ de la Crítica del juicio le atribuía a la naturaleza lo sublime, es decir, una belleza artística intrínseca a la belleza natural que se hacía patente a través de la mediación del artista. La belleza se conjugaba en el campo 
de lo natural y lo artístico, por lo que el canon de lo bello continuaba históricamente envolviendo la forma, tomando las partes de los contenidos sociales y económicos, así como los psicológicamente fantasiosos que el propio sujeto producía y plasmaba en sus obras. Esto cambió con Hegel y los románticos, que elaboran un arte más allá de lo vanidoso y de la mimesis total y perfecta de lo natural que tiene en cuenta la expresión sensible de artista. Se empieza por tanto a entretejer una dialéctica entre la naturaleza primera (carácter autónomo de lo bello natural) con la naturaleza segunda (carácter social de la obra de arte incrementado a partir de la Revolución Industrial). Así es que, entre otras cosas, al entrar en el curso del siglo XIX, el ámbito del paisaje cultural (Adorno, 2014, 91), las obras abandonan una parte del ámbito de artefactos. Dice Adorno que a lo largo del siglo XIX:

[S]e siente como bellas las obras históricas, a menudo en relación con su entorno geográfico, al que por ejemplo se pueden parecer por el material pedregoso empleado. En ellas no es central, como en el arte, una ley formal; rara vez están planificadas, aunque su orden en torno a la iglesia o a la plaza del mercado tiende a veces a algo de este tipo, igual que las condiciones económico-materiales a veces producen formas artísticas. Sin duda, no poseen el carácter de intangibilidad que la concepción habitual suele asociar a lo bello natural. A los paisajes culturales, la historia se les ha impreso como su expresión, la continuidad histórica como su forma, y los integran dinámicamente, tal como suele suceder en las obras de arte (Adorno, 2014, 91).

A partir del goce estético por el paisaje cultural, el arte cada vez más se decanta hacia los contenidos sociales, debido a una apropiación y un interés por parte de los nuevos artistas en el componente real e ideológico urbano además de en los estigmas estéticos de la sociedad de mercado. Aunque, el paisaje cultural como forma, a la vez, no deja de estar preso del continuismo objetivista de la mímesis natural bajo el que la propia naturaleza se ensalza como belleza de un entorno concreto. El paisaje cultural se representa como una reserva natural, así concebida por la expresión artística, sobre la cual los objetos de la realidad se presentan idealmente siguiendo los criterios del formalismo mimético del siglo XVIII.

Por ende, partiendo del ideal de belleza natural, del canon, del principio de armonía, de proporción y de equilibrio, esto es, de los fundamentos de la teoría estética del siglo XVIII (i. e., Winckelmann, Batteux, Baumgarten, Kant, etc.), se llega a conectar de algún modo lo bello natural con el espíritu histórico y material de la época. El reflejo de los artistas del siglo XIX en los contenidos sociales 
e históricos se desarrolla a la par que la reconstrucción del principio formalista anterior. Este nuevo conflicto dialéctico va a acabar con aquella ensońación rousseauniana del retournons al estado de la naturaleza pacífico y primigenio, y, por tanto, traerá la confusión de las leyes de la naturaleza con las humanas (i. e., lo que en muchos casos consiste en no distinguir la zoología y la biología de la política). En el siglo XIX, con la implantación progresiva del modo de producción capitalista en Europa, pierde fuerza aquel idealismo iusnaturalista y se empiezan a componer todo tipo de ambigüedades entre la experiencia natural y las funciones integradas en la llamada cosificación social (segunda naturaleza), contextualizada en espacios más cercanos a las relaciones sociales y a las relaciones entre individuos (población) de un territorio (p. e., para los liberales estas relaciones vienen dadas como un mecanismo autorregulado natural que va desde las ideas del reverendo Joseph Townsend, Condorcet, Malthus, Darwin, Spencer, etc.).

En este contexto filosófico y político, tal es el movimiento estético de emancipación de la burguesía que, en nombre de los derechos humanos (lo que implica el idealismo de la humanidad), siente el afecto común por los prados de color lila, las muñecas de porcelana (con un decoro un tanto siniestro) y las músicas populares de raigambre repetitiva y sincopada (p. e., las músicas folclóricas, el ballet, la música de salón del siglo XIX, etc.). Esto conlleva una nueva adopción de la inmediatez de lo natural (un tipo estético de naturalismo) mediada por aspectos sociales que envuelven la esfera de lo dado y la transforman. El kitsch, con su anverso la vanguardia, como diría Clement Greenberg, nos da razones para entender la industria turística del paisaje romántico vinculado a las grandes urbes y de cómo se sublima el sensorio geológico fusionado, al mismo tiempo, con la belleza natural mediada por aspectos inmanentes a la sociedad. Las costumbres burguesas, moral-narcisistas, se reflejan en los anuncios publicitarios de la sociedad de mercado, esto es, en la apariencia y el fetichismo que se eleva como segunda naturaleza de la circulación de mercancías y de los intercambios comerciales. Lo que tiene salida a ese bello natural se vuelve ideológico, fetichista, consumista y sujeto a la inmanencia social. Por ello, dice Adorno: "lo bello natural es una alegoría de eso que está más allá, pese a estar mediado por la inmanencia social" (Adorno, 2014, 98). 


\section{Adorno y Greenberg. Teoría de la vanguardia y del kitsch}

En la Filosofia de la nueva música, Adorno nos comenta lo siguiente sobre Clement Greenberg:

La música participa de lo que Clement Greenberg llamó la división de todo arte en kitsch y vanguardia, y el kitsch, el dictado del beneficio sobre la cultura, hace tiempo que ha sometido la esfera particular socialmente reservada a ésta. Por eso las reflexiones que se ocupan del despliegue de la verdad en la objetividad estética se refieren únicamente a la vanguardia, la cual está excluida de la cultura pública. Hoy día, una filosofía de la nueva música únicamente es posible en cuanto filosofía de la nueva música. Como defensa no cabe sino la denuncia de esa cultura: esta misma únicamente ayuda al fomento de la barbarie contra la que se indigna (Adorno, 2003, 19).

En el año 1961, el crítico de arte neoyorkino Clement Greenberg publica en Boston la obra Arte y cultura, que contiene un texto titulado "Vanguardia y kitsch", donde se hace un diagnóstico de las dos formas estéticas que se desarrollan en el seno de las sociedades burguesas occidentales del siglo XIX: la vanguardia y el kitsch. Por una parte, en lo que respecta a la primera, se produce una nueva forma de manifestación estética que contiene el fundamento de una resistencia, la crítica histórica, social y política además de un análisis de las causas, efectos, antecedentes y funciones del orden social burgués (Greenberg, 2002, 16). Esto es lo que Greenberg denominó "la cultura de la vanguardia" (Greenberg, 2002, 16). En los años cincuenta y sesenta del siglo XIX, esta corriente avanzó a través del flujo migratorio de la bohemia, que llevaba parejo el modelo del mercado capitalista que se situó como una salida para los artistas, poetas, novelistas y ensayistas ante la decadencia del viejo mecenazgo aristocrático del arte (Greenberg, 2002, 17). La forma estética que surge de estas condiciones es la vanguardia, esto es, una forma distanciada de la sociedad, pero desde dentro de ella, capaz de dirigirse contra un tipo determinado de clase social a la que considera políticamente degradada. El espíritu revolucionario del siglo anterior se reproduce estéticamente en una especial confusión entre ideología y violencia (Greenberg, 2002, 17), del medio de las buhardillas, las callejuelas, las ruelas, las plazas y los barrios sale una forma que es capaz de rechazar el poder aristocrático desde una posición de clase burguesa que busca hacer la guerra a través del arte y la cultura. La revolución quedó introducida en el corazón de las ciudades modernas, una nueva creencia individual, de aquel poeta y artista que saca de su regocijo subjetivo una forma 
de elevación y sublimación de su deseo consumado en la marginación social para mostrarse atacante ante un orden social antiguo y opresor que necesita ser vengado. El curso histórico del arte, sigue también la dialéctica que va de lo subjetivo a lo absoluto, y de lo concreto a lo abstracto. Así, el desarrollo de un sujeto romántico idealista continúa por la vía estética, a la vez que por otros cauces (p. e., nacionales, y por tanto políticos). La vanguardia, también se erige dejándose ver en formas particulares más singulares que los tratados metafísicos y epistemológicos de las épocas anteriores, no así también se envuelve del contenido absoluto, idealista y metafísico anterior, aunque reproduzca formalmente una diferencia que tiene una nueva validez estética.

En el caso de la música, se trata de conseguir producir un constructivismo, que comienza en la vanguardia, como expresionismo (p. e., en Alemania) e impresionismo (p. e., en Francia), hasta llegar a un dodecafonismo (p. e., en Viena), a través de unas estructuras musicales que van de lo más grandioso de la totalidad hasta lo más pequeño, breve y minúsculo, así como de lo más orgánico a lo inorgánico (i. e., de lo tonal a lo a-tonal), tal y como lo demostraron Schönberg, Berg, Webern, Steuermann, Kolisch, etc. A este respecto, Adorno en el texto "Fragmentos sobre música y lenguaje", de los Escritos musicales II, incluye a Pierre Boulez, que evoca tanto a Webern como a Debussy (Adorno, 2006, 669), aunque también muestra la proximidad de este con la nueva composición de la música concreta defendida desde una perspectiva objetualista y fenomenológica por su profesor Schaeffer ${ }^{1}$. Desde la vanguardia musical, sobre todo a partir del impresionismo francés y del expresionismo alemán, se tiende hacia el carácter inorgánico de la obra, esto es, hacia la ruptura con el sistema armónico tonal de la música y, por supuesto, con el sistema representativo y mimético naturalista del arte visual (el paso de la alegoría al símbolo hasta la vanguardia como nuevo arte inorgánico). Ahora, como ya explicita Peter Bürger ${ }^{2}$ en su Teoría de la

${ }^{1}$ Se apela aquí al texto que Pierre Schaeffer publica en Editions du Seuil (en 1966) titulado Tratado de objetos musicales. En este texto nos dice Schaeffer que hay tres nuevos hechos en la música que se revolucionan la música. En primer lugar, un hecho de naturaleza estética basado en la libertad cada vez mayor a nivel de reglas armónicas y de estructuras musicales (i. e., transformaciones a lo largo de la historia de la variación y la forma disonancia). El segundo hecho concierne a la llegada de nuevas técnicas y de los nuevos dispositivos musicales tanto de la llamada música concreta (nacida en 1945) como de la música electrónica (de 1950). El tercer hecho está formado por los descubrimientos de nuevos fenómenos musicales en la etnología que da lugar a la comprensión de nuevos objetos sonoros poco cifrables bajo el sistema del lenguaje musical occidental (Schaeffer, 2003, 19-23).

${ }^{2}$ Peter Bürger, en su famosa obra titulada Teoría de la vanguardia, de 1979, se refiere a este carácter orgánico e inorgánico de la obra de arte al empezar el tercer capítulo titulado "III. La 
vanguardia de 1973, este carácter inorgánico de la obra vanguardista conlleva también una mediación con los contenidos de verdad y la praxis social, así como con el momento histórico que ocupa dicha obra. Frente al carácter orgánico del símbolo, en el que esta mediación se ve reducida (por la relación unívoca entre totalidad y partes), la obra vanguardista es un revulsivo contra el arte institucionalizado y oficializado. La escala de seis notas de Debussy y el dodecafonismo de Schönberg son ejemplos cruciales de cómo el carácter orgánico del sistema tonal del Barroco (lo que en el arte visual era el símbolo) entra en decadencia, ante la aparición de una fuerza productiva musical que tiende a lo inorgánico (es decir, el concepto de lo artificial frente al concepto de vida orgánica que recuerda al concepto de la filosofía de la naturaleza hegeliana) y a la mediación social de la obra; lo cual, significa una vuelta al arte inorgánico y mediado que anteriormente encarnaba la imagen alegórica. Por tanto, el material de composición debe arrancar de sí la fuerza orgánica del sistema tonalista del lenguaje, anclado como forma natural a lo largo de la historia de la música, para que así nos lleve hacia una: "mediación entre sujeto y objeto" (Adorno, 2006a, 670), que consiste en:

[E]xtraer mediante el oído del mero material el lenguaje que éste incluye, deviene uno interior al sujeto que se esconde en ese material; al extraer los elementos lingüísticos, que son todos ellos emociones subjetivas

obra de arte vanguardista", en el punto primero "La problemática de la categoría de obra". Aquí, apela a Adorno para hacer referencia a la cita de Filosofía de la nueva música que dice: "Hoy día las únicas obras que cuentan son las que no son obras" (Adorno, 2003, 36). Y, con esto, Adorno señala distintos ejemplos de obras de este tipo, en el contexto de la primera época expresionista de Schönberg, como lo son: el monodrama Erwartung y el Wozzeck de Berg (aunque a este último no le hubiera gustado realizar las piezas expresionistas al modo schönbergiano en su ópera). Sobre esto, comenta Bürger que: "La enigmática sentencia de Adorno emplea el concepto de obra en un doble sentido: por un lado, en un sentido general (y desde el punto de vista el arte moderno todavía tiene carácter de obra); por otro, en el sentido de obra de arte orgánica (Adorno habla de "obra redonda»), y es este concepto limitado el que destruye la vanguardia. Esto nos vale, pues, para distinguir entre un significado general del concepto de obra y un determinado uso histórico. En un sentido general, la obra de arte se establece como unidad de generalidades y particularidades. Esta unidad, sin la cual no puede concebirse una obra de arte, se realiza, sin embargo, de modos muy diversos en las distintas épocas del desarrollo del arte. En las obras de arte orgánicas (simbólicas) la unidad de lo general y lo particular se da sin mediaciones; en las obras inorgánicas (alegóricas), por el contrario, entre las que se encuentran las obras de vanguardia, hay mediación. Aquí el momento de la unidad está en cierto modo contenido muy ampliamente, y en el caso extremo sólo lo produce el receptor. (...) La obra de vanguardia no niega la unidad en general (aunque incluso esto intentaron los dadaístas), sino un determinado tipo de unidad, la conexión entre la parte y el todo característicos de las obras de arte orgánicas" (Bürger, 2000, 111-112). 
sedimentadas, de su contexto ciego, por así decir desarrollado de forma natural y él mismo exhaustivamente construido de manera pura, se hace justicia a la idea de objetividad que es propia de todo lenguaje en medio del subjetivo significar (Adorno, 2006a, 670).

Dicho esto, frente a ese impulso eternizador, épico, hasta estático, de eso que Greenberg llama "alejandrismo" (Greenberg, 2002, 20) se establece la vanguardia como una reformulación de esos contenidos nacidos en la mayor intimidad y subjetividad del sujeto burgués que busca lo contingente del devenir, y que quiere seguir la estela de lo que se mueve históricamente, pero de lo que se mueve contra aquello que, al fin y al cabo, representa la clase dirigente. Esta clase dirigente que cada vez más abandona la cultura (Greenberg, 2002, 20), deja hueco para que una base social se apropie de esa fuente. Pero que la vanguardia quede como la restauradora de un contenido que se empieza a pensar anacrónicamente, su forma es la que expresa la novedad, la deja abocada también a cierto peligro que se corre en tanto abarcar. Los espectáculos multitudinarios, las universidades, las editoriales, la mezcla entre lo académico y lo comercial, conllevan también un espacio de mercado de bienes, servicios y personas que necesita su precaución. No así, como dice Greenberg "la vanguardia empieza a sentirse insegura del público del que depende: los ricos y los cultos" (Greenberg, 2002, 21), así es que: "donde hay vanguardia generalmente encontramos también retaguardia” (Greenberg, 2002, 21); y aquí ya entramos en la segunda forma que señalábamos como propia del ambiente estético-social de mediados del XIX: el kitsch. Este segundo fenómeno, contrapuesto dialécticamente con la vanguardia, pero ambos mutuamente epocales, contextuales y dentro del mismo tipo de clase social, está conformado por ese tipo de arte de cromotipos y falsas reliquias, literatura de cómics, revistas en papel satinado, con dibujos extravagantes y titulares coloridos con espirales y roscas. El kitsch es la forma estética del consumo fruto del marketing decimonónico, de la mercadotecnia de la música pop (p. e., el ballet), de los artilugios singulares de la burguesía a la venta que son una forma estética, una forma de entretenimiento y a la vez una mercancía que residualmente había generado el impulso industrial y capitalista en ese siglo. Así como donde hay ortigas se puede encontrar menta, así también el kitsch y la vanguardia conviven como dos fenómenos imbricados que surgen de un modo paralelo en el mundillo del arte, la literatura, la cultura y el comercio. Tanto el kitsch (anterior históricamente) como la vanguardia se dan en las formas de vida urbanas, en la burguesía con tiempo libre que busca su zona de confort más allá de la satisfacción de las necesidades vitales más básicas. El tiempo se mata recurriendo al consumo de nuevos productos culturales, que actúan como pasatiempo. A veces con una forma de revancha, de crítica negativa 
y resistencia política, como es la vanguardia, pero otras veces dejándose llevar por lo que ofrece el comercio, disfrutando y creyéndose lo que se oferta en un alarde de cursilería, a saber, el kitsch. Greenberg nos dice que el kitsch: "es un producto de la revolución industrial que urbanizó las masas de Europa occidental y Norteamérica y estableció lo que se denomina alfabetismo universal" (Greenberg, 2002, 21). Las distracciones de las masas urbanas inspiran este tipo de forma estética que es el kitsch, el cual dice Greenberg consiste en el paso del gusto por la forma popular de las clases sociales anteriores (medievales y renacentistas heredadas de una cultura popular frente a la oficial) hacia una "cultura sucedánea" (Greenberg, 2002, 22). En este sentido hay un cambio de forma de la cultura popular a una cultura de masas, de un modo de producción feudal a uno capitalista, y por tanto, de un modo de entretenimiento, de hábitos, de costumbres sociales y estéticas que intenta regenerarse y situarse en detrimento del alejandrismo anterior. Los contenidos entran en crisis, el mercado los convierte en mercancía, en el kitsch surge una regresión y en la vanguardia la agresión, por decirlo así. No obstante, ambos fenómenos son efectos de la caducidad de unos contenidos alejandrinos, épicos, económicamente feudales, pero también populares, es decir, se quieren reincorporar a una época de acumulación capitalista que empieza a generar nuevas necesidades, por lo tanto, nuevos cambios formales de esos contenidos que con el paso del tiempo se van volviendo anacrónicos. Estas formas, en el caso de kitsch, son mecánicas, se ligan a la máquina, utiliza fórmulas (Greenberg, 2002, 22), estereotipos y estilos que siguen el mismo patrón: "epítome de todo lo que hay de espurio en la vida de nuestro tiempo" (Greenberg, 2002, 22). Se rompe el canon de belleza clásico, natural, pero también lo sublime, la mimesis cobra otra forma, en preferencia a la cursilada romanticona degenerada que cuesta dinero y que cierra la puerta a mercados tradicionales, amanuenses, artesanías, gremios de madereros, o cuanto menos los liga al movimiento de reproducción mecánica de la máquina y de la producción industrial capitalista. El kitsch, en su apego al academicismo, avanza triturando, vaciando, degenerando, haciendo decaer y sobre todo desnaturalizando las formas de la cultura popular y aristocrática anterior restaurándose a la vez con una intención de parecer aristocrática no siéndolo en un afán intermedio, confuso y borroso, que estéticamente abre cancha para anclar al nuevo orden social burgués. Lo cortés se hace ridículo, lo fino se hace ostentoso, la valentía se amanera y remilga, el honor se hace presuntuoso, lo noble pretencioso y lo pobre ostentoso. La simpleza de lo artesanal se hace espectacular, fastuosa y aparatosa, se imita lo lujoso, pero no es más que jactancia, fanfarria y petulancia. Por ello también hay un kitsch épico nacional, incluso noble, de paisajes de caza en los halls de los hoteles y en los salones junto a las chimeneas, las lámparas de colores chillones, la cromatización del motivo 
arabesco, una especie de gusto por el chicle y el plástico postinero, pomposo, plúmbeo y rimbombante.

Adorno analiza esta forma del kitsch en la música a través de sus trabajos críticos con el ballet ${ }^{3}$, el jazz y los evergreens. Este último ejemplo de la música

\begin{abstract}
${ }^{3}$ Fredric Jameson, en Marxismo y forma, explica la dialéctica subjetiva y objetiva, seguida de la dialéctica entre forma y contenido que se da en el ballet de Stravinsky frente al expresionismo schönbergiano, de un modo clarividente. Veamos cómo lo cuenta: “(...) en una situación en la que lo subjetivo y lo objetivo ha empezado a separarse, la originalidad de Schönberg fue la de haber conducido lo subjetivo y lo expresionista hasta su límite extremo, hasta el punto en el que las imágenes de los nervios y los traumatismos de este último viran lentamente, bajo la presión de su propia lógica interna, hacia la nueva objetividad, el orden más total, del sistema dodecafónico. Tal vez lo mejor sea comprar la especificidad de esta solución con la diametralmente opuesta de Stravinsky, de quien podría considerarse que trabajó desde el otro polo del dilema moderno, el objetivo. Porque ya la forma privilegiada en la que trabaja Stravinsky, el ballet, puede considerarse una especie de música aplicada que, incluso de manera más drástica que la «música programática» de la que es contemporánea, reinventa una especie de distancia entre contenido y forma dentro de un medio por lo demás no figurativo. De ese modo logra evitar los problemas de autojustificación y autodeterminación afrontados por la música pura y resueltos por Schönberg de la manera aquí descrita: porque su práctica musical ya está, por así decirlo, justificada por el propio retablo visual y, a posteriori, por los movimientos físicos de los bailarines, que la ratifican y de los que acaban pareciendo acompañamiento. Y lo que ocurre a la forma de estas obras se reproduce en el plano del contenido en sí, particularmente en los ballets rusos. Tanto Petrushka como La consagración de la primavera dramatizan el sacrificio de la subjetividad individual a una colectividad inhumana, y su primitivismo deliberado (con el llamamiento a la cultura popular en Petrushka o L'Histoire du soldat, y con sus elementales, arcaicos y casi imposibles ritmos prehistóricos en La consagración de la primavera) solicita la regresión del oyente/espectador culto a una especie de sacrificio del intelecto en el completo emocionalismo de la respuesta masiva. Este primitivismo ultraculto o demagogia musical (Adorno llega a compararlo como fenómeno al fascismo) se inscribe en la técnica de las obras en sí, la cual, como algo opuesto a los principios organizativos totales de Schönberg, favorece una especie de verticalidad masiva y discontinua. Sus ritmos y repeticiones rituales están rotos por lapsos y silencios que crean una sincopación con las recurrentes ondas sísmicas de las reacciones corporales de oyente. A diferencia de Schönberg, Stravinsky organiza los elementos implicados de acuerdo con categorías extrínsecas a la estructura musical, como las cualidades o los colores aislados de los propios instrumentos, o los efectos psicológicos de sus oposiciones (alto y tenue, penetrante o masivo). A buen seguro, Stravinsky, y en especial el Stravinsky de los primeros ballets, supone un fenómeno musical tan influyente y primordial como el del propio Schönberg; pero es instructivo comparar las respectivas situaciones históricas de las que cada compositor derivo las innovaciones (...). El valor y la dirección de la práctica artística de Stravinsky pueden juzgarse en último término por la larga serie de pastiches neoclásicos que sucedieron al periodo ruso. Porque, en ellos, la inclinación hacia la objetividad musical puede observarse abiertamente en el modo en el que el compositor renuncia a su propia voz, abdicando de ese estilo personal que se ha vuelto problemático en los tiempos modernos y hablando a través de la subjetividad fosilizada de compositores
\end{abstract}


ligera que trata Adorno en la segunda lección titulada "Música ligera" (Adorno, 2009, 199-219) de la "Introducción a la sociología de la música" (Adorno, 2009, 177-419) consiste en: "canciones de moda que parecen no envejecer y que sobreviven a las modas" (Adorno, 2009, 215). Con evergreens, se refiere a canciones que tuvieron fama en el momento en que se ofertaron y se van repitiendo a lo largo de distintas generaciones. Estas canciones de moda que van conformando el repertorio musical son productos musicales que se diferencian de otras canciones que pasan desapercibidas de un modo efímero ya que no llegaron a constatarse históricamente en un tiempo prolongado. Estas canciones populares y de moda que son un verdadero fenómeno del kitsch musical, según Adorno: "en América figuran como nostalgia songs" (Adorno, 2009, 215-216), copan las listas de popularidad gracias a una apariencia cosificadora manifiesta que atrae al consumidor a partir de mecanismos psicológicos basados en la espontaneidad, la cercanía, la humanidad, el gancho, la garra, lo casero, el morbo y hasta lo cutre. Ahora bien, esta estrategia psicológica de captación no es sino el efecto y resultado de un "dominio del aparato publicitario" (Adorno, 2009, 217) y de sus intereses económico-políticos.

\section{La decadencia de lo bello y el carácter enigmático de la obra de arte}

Toda aquella experiencia estética kantiana basada en lo sublime y en los fenómenos naturales subyugados, grandiosamente pasados por un mimetismo natural (elevado, excelso, insigne idílico, eximio, celestial, puro, etc.), se empiezan a retorcer con la entrada del punto de vista histórico del artista moderno. Lo imitable pasa de ser la cualidad física más trascendental de la naturaleza, a ser parte de su naturaleza inmanente, en tanto que situada histórica y socialmente en el mundo tecnológico e industrial del siglo XIX. La perfección de las formas media la crudeza de los contenidos y la mímesis natural es también una mímesis social, en tanto que se transfieren nuevos elementos inmanentes a la realidad ( $\mathrm{p}$. e., plazas, mercados populares, iglesias, calles, tiendas, versus, pasajes, bulevares, centros comerciales, grandes almacenes, etc.). El componente mimético de la

muertos, en una especie de ingeniosa farsa estilística que revive formas fantasmagóricas de un pasado en el que la composición musical estaba aún libre de contradicciones internas" (Jameson, 2016, 32-34). 
obra de arte moderna plasma la nueva naturaleza de la tecnología y su mundo industrial, eso que Benjamin (2010) llamaba ur-naturaleza y Lukács (2016) denominó segunda naturaleza.

Así es que el paisaje grandioso y escarpado ante el sujeto solitario, la felicidad del abandono en las zonas costeras y montańosas pasa en el momento presente por la ruta de senderismo y la casa rural del turista alpino. La grandeza sublime y abstracta de la naturaleza de Kant, está actualmente circunscrita a la órbita social del comercio en lo que respecta al sector servicios y a los escaparates de las agencias de viajes que publicitan packs de viajes-ahorro con rutas seguidas por calzadas pavimentadas y piscinas climatizadas. El apriorismo de la teoría estética, intrínseco a la distinción entre las categorías de lo bello y de lo feo, queda hoy, en sus efectos, en el vacío de una estética donde triunfa lo que vende, lo que se muestra en los escaparates de las tiendas, en los paneles de publicidad, en los anuncios televisivos y en toda clase de productos ofertados con mejor o peor éxito en las redes sociales (i. e., el valor se mide por los "favoritos", "likes" y "emoticonos" que cierran el gusto estético en el mero psicologicismo sensacionalista de las demandas masivas). Pero: ¿son estas nuevas manifestaciones parte del arte bello, de lo sublime, del arte digno, del arte libre, de lo kitsch, del arte de vanguardia, del arte contemporáneo? La respuesta que aporta Adorno a esta problematización de la situación presente respecto al concepto estético de belleza está marcada característicamente por su indefinibilidad respecto a la idea de naturaleza. Pues la naturaleza de Kant (1999), en la que se daba esa autonomía formal de la experiencia estética ni siquiera era la de física (ni la de Newton), ni la de los siglos XVII-XVIII.

Sobre la metamorfosis que va de lo bello a lo kitsch ${ }^{4}$ dice Adorno que: "de una manera no especialmente ingeniosa se ha notado a menudo que las imágenes kitsch han echado a perder las puertas de sol" (Adorno, 2014, 102). Las puertas del sol, en tanto elementos lumínicos de la naturaleza que resultan bellos al juicio sensible sobre el fenómeno percibido por el sentido de la vista humano, han sido

\footnotetext{
${ }^{4}$ En la Primera parte de la Dialéctica negativa, Adorno asume que a mediados de los años sesenta este kitsch sigue igualmente presente en la filosofía. El diagnóstico de Adorno es que el kitsch perdura en las nuevas filosofías del siglo XX como un elemento vinculado a distintas concepciones del mundo y filosofías del ser cada vez más imperantes. Dice: "Sobre las filosofías restauradoras de hoy en día arroja luz el exotismo kitsch de concepciones del mundo de artesanía, como el budismo zen que tan asombrosamente bien se consume. Como este, simulan aquella posición del pensamiento que la historia acumulada en los sujetos hace imposible adoptar" (Adorno, 2005, 74).
} 
cambiadas por la luz artificial e inorgánica de las imágenes kitsch. Esto es, lo bello natural se define ya como una indeterminación, que vale para el objeto tanto como para el concepto, el arte deja de imitar a la naturaleza bella y mítica, y pasa a imitar a la nueva naturaleza historizada compuesta de ruinas. La historia mítica (fetiche), la historia natural (fósil) y la naturaleza mítica (la imagen del deseo) y la naturaleza historizada o histórica (la ruina), como lo enseńó Benjamin ${ }^{5}$, conforman una constelación que muestra las relaciones y transformaciones de los efectos causados por un modo de producción determinado.

Asimismo, volviendo al párrafo anterior, se podría decir que Hegel se inclina a lo bello artístico frente del bello natural, ambas categorías estéticas kantianas, el idealismo objetivo hegeliano emana del idealismo formal de la libertad kantiana, conservando también el dualismo filosófico del espiritu objetivo y del espiritu subjetivo. Dice Adorno en la Teoría estética que en esa belleza natural la promesa repentina de algo superior, es preciso liberarla a través de la conciencia que se le contrapone (Adorno, 2014, 106); y esto conserva el parentesco entre Hegel y Kant. Ahora bien, la crítica que hace Hegel al ideal de lo bello natural consiste en la recuperación de la conciencia artística del sujeto ante el rechazo al formalismo estético propio del idealismo naturalista del siglo XVIII, que tanto repudiaban los nuevos burgueses del siglo XIX. Hegel se vuelve reacio a aceptar la categoría de la belleza natural en sí, entendiendo que esa naturaleza es partícipe de algo más subjetivo y, a la vez expresivo-artístico que esas relaciones meramente formales, armónicas y proporcionalmente matemáticas de la idea de naturaleza kantiana. Contra esa naturaleza fundamentada matemáticamente del siglo XVIII, Hegel aplica las reglas contrapuestas del espiritu vivo, de lo subalterno y lo trivial en desprecio por la estética racionalista (Adorno, 2014, 106). El idealismo de la naturaleza se envuelve por el idealismo del espiritu, y artísticamente hablando, se enfrenta el espíritu objetivo a través y en contra del espíritu subjetivo, como anuncio de una nueva vocación propiamente humana que produce nuevas obras que van más allá de la reproducción real de las cosas naturales. Hay pues una transición o un desarrollo, para Hegel, del bello natural al bello artístico, es decir, de

\footnotetext{
${ }^{5}$ En la obra Dialéctica de la mirada. Walter Benjamin y el proyecto de los Pasajes de Susan BuckMorss se desarrolla esta constelación compuesta por la historia natural (el fósil), la historia mitica (el fetiche), la naturaleza histórica (la ruina) y la naturaleza mitica (la imagen del deseo) (Buck-Morss, 1995, 65-226). Esta constelación de ideas que integra la historia-natural le permitía a Benjamin diferenciar los elementos inmanentes al estadio prehistórico de la historia presente, a partir del cual se desvela la paradoja que, ante la nueva naturaleza del mundo tecnológico-industrial, se hacía patente en la era moderna después de la revolución industrial y el progreso técnico imparable del capitalismo avanzado de principios del siglo XX.
} 
la naturaleza al arte en el que: "no se encuentra la famosa equivocidad del verbo aufheben «superar y conservar»" (Adorno, 2014, 107).

En la Estética de Hegel (2002) el movimiento de superación en la identidad sintética (concepto subjetivo-objetivo-absoluto) no sigue el mismo curso que en otras obras, aunque la filosofía del espíritu subjetivo tiene su despliegue en el arte, así como el desarrollo del espíritu objetivo lleva a la religión, y el absoluto a la ciencia-filosofia (Wissenschaft). Ahora, Adorno muestra tal movimiento de la dialéctica de la superación hegeliana para enfrentarla ante Kant, enseñando el sentido dialéctico negativo y de contrapunte teórico-estético que va desde lo bello natural a lo bello artístico. Frente a la concepción clasicista de lo bello natural de Kant, Hegel sacrifica lo bello natural al espíritu subjetivo en su pretensión productiva artística, expresiva e imaginativa de alcanzar lo absoluto. Esto es, para Hegel, en la Estética, lo bello natural solo merece ser llamado así si se refiere al espiritu, porque el espíritu es superior a la naturaleza y sus fenómenos, y, por tanto, lo bello artístico es superior a lo bello natural porque es producto del espiritu (Hegel, 2002, 8-10). Y aquí es preciso matizar que esta estética hegeliana sigue siendo la del desarrollo, más que la de la oposición dialéctica, aunque tanto Kant como Hegel compartan la idea común de una teoría estética en relación con la categoría de lo bello como tal. No obstante, también se puede apuntalar que esta dialéctica estética avanza sin dejar ningún elemento atrás (i. e., envolviendo), debido a que en la crítica también se conservan los contenidos a los que se hacen referencia, a saber, los que son o se dicen formalmente bellos. Por ende, puede seguir leyéndose, al modo de una filosofía idealista sobre la belleza, una teoría estética que se piensa abocada al sujeto como espacio de la verdad y autonomía estética.

Dicho esto, estas distintas teorías, que luchan históricamente por la hegemonía estética, se mezclan, dice Adorno, con el carácter enigmático de las obras de arte (Adorno, 2014, 164). Hay, por tanto, una relación entre el carácter enigmático de las obras y el carácter histórico de las mismas, es decir, a lo largo de la historia, las obras se convirtieron en enigmas. Esto quiere decir que al carácter racional y formal de la planificación de un criterio estético siempre se le escapan elementos que pertenecen al caos que reina en el azar. Este modo de escapada, al modo de un clinamen, deja paso a cierto tipo de pensamiento negativo y en suspenso ante el momento más inmediato con la obra. Momento en el que la referencia de la obra se pone en relación con esa referencia que no se $d a$. Este vaivén enigmático característico a las obras de arte es, también, el modo dialéctico negativo en que Adorno escribe la Teoría estética. 
Todas las obras de arte, y el arte en conjunto, son enigmas; esto ha irritado desde antiguo a la teoría del arte. Que las obras de arte digan algo y al mismo tiempo lo oculten es el carácter enigmático desde el punto de vista del lenguaje (Adorno, 2014, 164).

Esto es, desde el punto de vista del lenguaje, una obra se vuelve similar al lenguaje-objeto mediante la forma de esta, no obstante, justamente por el peso de los contenidos, a tal obra también le son inmanentes el tema, los materiales, las técnicas aplicadas, su contexto social y económico. Pero en la relación entre la obra (p. e., la imagen o el sonido) y el sujeto perceptor no hay algo así como una codificación de antemano con los conceptos del artista productor. Al perceptor de la obra se le escapan cantidad de elementos que pueden estar detrás de la obra, funcionando como formas que organizan esos contenidos. Esto deja al receptor de la obra bajo un carácter lingüísticamente no contextualizado e, incluso, ininteligible. Esta situación, por muy conceptual que pueda ser la obra, eximia causa, niega el carácter total de lenguaje de la obra de arte. Por ello, para Adorno, a la obra ante el perceptor, se le escapa algo que es desconocido, rehúye de su autonomía, y se vuelve enigmática. Siguiendo ese punto de vista del lenguaje, el enigma resalta la parte indecible, inefable, irresuelta y muda de la obra. Este estado de asombro, que Adorno explica mediante el ejemplo del lenguaje de la música:

La persona que no entiende el lenguaje de la música, que sólo percibe galimatías y se pregunta qué son esos ruidos, puede asegurarse elementalmente del carácter enigmático del arte; la diferencia entre lo que esta persona oye y lo que oye la persona iniciada circunscribe el carácter de lo enigmático (Adorno, 2014, 165).

Esta reunión del carácter autónomo y social de la obra en el carácter enigmático se da en el modo en que también ante la obra de arte hay un estado de asombro, de desconcierto, de extrañeza, de impenetrabilidad y de desconocimiento. Adorno asocia este carácter enigmático ${ }^{6}$ con el sentido interrogativo de

\footnotetext{
${ }^{6}$ En la Filosofía de la nueva música hay unas páginas donde Adorno habla sobre el método dialéctico, a partir del cual destaca que lo más interesante no es convertir a la dialéctica en una religión del Estado (el método dialéctico "patas arriba", como dijo Marx de Hegel) sino que lo importante está en la transformación de la universalidad del concepto en una concreción intrínseca al objeto que solo es posible desde la resolución de la enigmática imagen social en la que se sitúa el individuo. Así lo dice Adorno: "El método dialéctico, y especialmente el que se asienta sobre sus pies en lugar de estar patas, no puede consistir en tratar los fenóme-
} 
la vida, en tanto que, el arte desconcierta a cualquiera que se precie a respuestas rápidas y sencillas. Ahora bien, esto no significa que Adorno defienda la pregunta como medio de comprensión de las obras, o se decante por la hermenéutica filosófica del arte en sentido gadameriano, pues no se trata únicamente de volver a producir las obras interpretativamente como juego (das Spiel) con la experiencia estética. No obstante, el carácter enigmático de la obra de arte hace a la propia comprensión una categoría problemática (Adorno, 2014, 166). Por ello, a veces ocurre que, cuanto más se intenta comprender una obra, más intenso es el sentimiento de insuficiencia y de incomprensión de la misma. La obra en su comprensión no es más que una ceguera puesta en el hechizo del arte, opuesta en su apariencia a todo contenido de verdad. Así dice Adorno: "cuanto mejor se comprende una obra de arte, tanto más deja de ser un enigma en una dimensión, pero tanto menos se esclarece su enigma constitutivo" (Adorno, 2014, 166). Esto es, el enigma no se puede resolver mediante tarea comprensiva alguna: "la imagen enigmática repite en broma lo que las obras de arte hacen en serio" (Adorno, 2014, 166).

Sin embargo, Adorno también cuenta que la comprensión no borra el carácter enigmático, pues hasta la mejor obra de arte quiere seguir siendo comprendida (Adorno, 2014, 167), la imaginación de las obras hace engañosa a la comprensión, pero ella no cesa en intentar mediar la obra. El receptor de la obra o el oyente musical puede intentar entender y captar perfectamente la obra en el sentido inmediato, al modo de la espiritualización del arte. Pero esta tarea está mediada por lo que escapa a esa comprensión, y tanto es así que el carácter enigmático se relaciona con un carácter doble que traspasa la total comprensión y el desconcierto. De ahí que Adorno exprese que: "aquello a lo que remite el carácter enigmático de las obras de arte sólo se puede pensar mediado" (Adorno, 2014, 167). No hay por tanto, en reducción, una suspensión fenomenológica de lo pensado en su inmediatez, sino que hay una mediación dialéctica negativa que pone en conflicto a la propia comprensión, a la vez, con la entrada en lo neutralizado (neutralisiert), que es el enigma. En la Teoría estética, podemos ver así, como Adorno llega a este punto de irreductibilidad a partir de este concepto (aconceptual) de enigma, como un enlace que desenlaza los polos para dar cueva a la: "duplicidad

nos individuales como ilustraciones o ejemplos de algo ya sólidamente existente y dispensado por el movimiento mismo del concepto; así es como degeneró la dialéctica en religión de Estado. Más bien se exige transformar la fuerza del concepto universal en el autodesarrollo del objeto concreto y resolver la enigmática imagen social de ésta con las fuerzas de su propia individuación" (Adorno, 2003, 32). 
entre lo determinado y lo indeterminado" (Adorno, 2014, 170) de las obras de arte y la articulación con su receptor-oyente situado en un devenir de momentos que es el curso de la historia.

\section{Conclusiones}

Cabe concluir que el desarrollo histórico de las ideas estéticas no cumple el plan de ninguna teleología, ni está cercado de antemano por un axioma científico-formal que determina la totalidad de la idea estética en sí ni para sí. La idea de lo bello, con el paso de los siglos, guerreó sobre si misma desde su tendencia más positiva-natural hasta la más subjetiva-romántica. La multiplicidad de formas de imitación plasmadas artísticamente está mediada dialécticamente por cantidad de conflictos que surgen a partir del embrollo histórico en el que se juega el momento presente. La lucha entre formas y contenidos de lo que cae bajo la categoría de lo bello romántico hasta el apogeo genial por lo sublime, se le responde en el siglo XIX con la vanguardia y lo kitsch como nuevas formas con nuevos contenidos. La aceleración del paso del modo de producción feudal al capitalista en el siglo XIX fue un momento que hizo cambiar los contenidos de verdad de las totalidades formales, trayendo consigo una revolución industrial que pone de manifiesto una nueva o segunda naturaleza industrial, tecnológica y administrada. Estos contenidos sociales son los efectos de tales causas económico-sociales y políticas, y en verdad, parcialmente, son también el sustrato afectivo y material del que surgen las obras de arte. El escenario social en sus efectos responde a las causas artísticas con las que perpetuamente se haya en mediación.

La Teoría estética de Adorno nos plantea un lugar para la verdad confuso para el análisis crítico de las obras de arte que, en su incompletud provocada por los inabarcables contenidos de verdad, está constantemente mediado por el carácter enigmático. El todo y las partes, la forma y los contenidos, el objeto y el sujeto, lo material y lo ideal, lo concreto y lo abstracto, la naturaleza y la historia, los efectos y las causas, están mediados en el curso histórico de las obras de arte con las cuales se hayan en conflicto, a saber, por su desconocimiento y desconcierto ante ellas, es decir, por el carácter enigmático inmanente a tal relación. Ahora bien, aun siendo así, esto no niega ninguna de las formas y contenidos en sí que se están recibiendo, observando, escuchando y hasta consumiendo como mercancías, sino que entiende que la crítica opera distinguiendo, disociando, separando y triturando las partes de las que está compuesta la totalidad. 
No obstante, de un modo hegeliano, se podría concluir que las relaciones que se establecen entre ellos (partes y todo, contenidos sociales y formas estéticas, sujeto y objeto) son dialécticas no solo debido a que hay un conflicto de uno contra el otro en el pensar, sino que también es necesario hacer alusión al plano dialéctico en el que compite la realidad social con las obras artísticas en sí y para sí mismas, en el ser (i. e., cualidad, cantidad, medida) y en la esencia (i. e., reflexión sobre sí misma, apariencia y realidad). En definitiva, desde la teoría estética y/o filosofía del arte, lo que se puede decir es que: el arte no es ni una ciencia ni una mera técnica, pese a contener en sus operaciones una pluralidad inabarcable de saberes, áreas y campos, su definición está cruzada por el enigma.

\section{Bibliografía}

Adorno, Th. W. (2003). Filosofía de la nueva música. Obra completa, 12, Madrid: Ediciones Akal.

- (2005). Dialéctica negativa. La jerga de la autenticidad. Obra completa, 6, Madrid: Ediciones Akal.

- (2006). Escritos musicales I-III. Figuras sonoras. Quasi una fantasia. Escritos musicales III. Obra completa, 16, Madrid: Ediciones Akal.

- (2009). Disonancias. Introducción a la sociología de la música. Obra completa, 14, Madrid: Ediciones Akal.

- (2014). Teoría estética, Madrid: Ediciones Akal.

BAudelaiRe, СH. (2016). El pintor de la vida moderna, Barcelona: Taurus.

Benjamin, W. (2010). Obras, vol. I, Madrid: Abada.

Buck-Monss, S. (1995). Dialéctica de la mirada. Walter Benjamin y el proyecto de los Pasajes, Madrid: La balsa de la medusa.

Bürger, P. (2000). Teoría de la vanguardia, Barcelona: Ediciones Península.

Grasset, J. P. (2012). "Schelling, arte vivo y naturaleza productiva”. Revista de la Academia, núm. 15, pp. 119-135.

Greenberg, C. (2002). Arte y cultura. Ensayos críticos, Barcelona: Paidós.

HeGel, G. W. F. (2002). Estética, Barcelona: RBA.

JAMESON, F. (2016). Marxismo y forma. Teorias dialécticas en la bibliografía del siglo XX, Madrid: Akal.

Kant, I. (1999). Crítica del Juicio, Madrid: Editorial Espasa Calpe. 
Lukács, G. (2016). Teoría de la novela, Barcelona: Penguin Random House Grupo Editorial.

SCHAEFFER, P. (2003). Tratado de los objetos musicales, Madrid: Alianza Editorial.

Schelling, F. W. G. (1988). Sistema del idealismo trascendental, Barcelona: Anthropos.

Este trabajo se encuentra bajo una licencia de Creative Commons ReconocimientoNoComercial-SinObraDerivada 4.0 